\title{
The application of quality management system in modern and small enterprises
}

\author{
LingLing Yu, JianBao Chang \\ Nanchang Institute of Technology, Nanchang, Jiangxi 330044, China
}

Keywords: Quality, Management, System.

\begin{abstract}
Small and medium-sized enterprises play an increasingly important role in economic prosperity, promoting growth, expanding employment and promoting innovation. It has become one of the key factors to promote the sustainable development of China's economy and society. Quality is the basis of enterprise's survival and the important content of enterprise's production and operation strategy. The implementation of the ISO9000 standard has become a hot spot in the enterprise circle and a new trend of enterprise quality management modernization. In this paper, the ISO9000 quality management system is discussed in the production management of small and medium-sized enterprises
\end{abstract}

\section{Introduction}

ISO9000 is the concept proposed by the international organization for standardization (ISO) in 1994. It refers to the international standards set by the ISO/Tc176 (international standardized quality management and quality assurance technology commission). ISO9000 standard technical standards is not a product, but the organizational structure, management personnel, technical skills, rules and regulations, technical documents, internal supervision mechanism and a series of organizations, to ensure the quality of products and services management measures. ISO9000 refers to the standard of quality management system. It is not a standard but a collective standard. ISO9000 is the best-selling and most popular product of the more than 12,000 standard issued by ISO

ISO9001 quality management system requirements Through ISO9001 certification, certification bodies have the ability to provide products and applicable regulatory requirements to meet customer needs to improve customer satisfaction. Commodity economy and the expansion of internationalization, in order to improve the reputation of our products, reduce duplication of inspection, weaken and eliminate technical barriers to trade, producers and maintenance, users and consumers' rights and interests of the parties, the third party certification is not affected by the economic interests of the production and sales, notarization, science, is the national evaluation and supervision over the quality product and company supplier quality system audit; Customer base; The company has the ability to meet the technical requirements of ordering products. Through ISO9001 certification, certification bodies have the ability to provide products and applicable regulatory requirements to meet customer needs to improve customer satisfaction. Commodity economy and the expansion of internationalization, in order to improve the reputation of our products, reduce duplication of inspection, weaken and eliminate technical barriers to trade, maintenance, users and consumers' rights and interests of the parties, the third party certification is not affected by the economic interests of the production and sales, notarization, science, is the national evaluation and supervision over the quality product and company supplier quality system audit; Customer base; The company has the ability to meet the technical requirements of ordering products. The main contents of the ISO9000 standard include: quality management system, management responsibility, resource management, product realization, measurement and analysis and improvement. The main principles of quality management include: customer orientation, leadership role, full participation, process, system management, continuous improvement. 


\section{The enterprise introduces the meaning and function of ISO9001 quality management system}

The enterprise quality management system is the mainstream system in the current enterprise standard management system, which plays an important role in improving the quality management level of the enterprise. ISO9000 standard as the international quality standards, reflects the enterprise as a representative of the organization's quality management system requirements management, the process and the basic train of thought as well as small and medium-sized enterprises provide a basis for the quality management and tools. ISO 900 international quality management system, adhere to the people-oriented, improve the staff's consciousness of learning, quality and customer orientation, IS09001 international quality management system focus on strengthening training mechanism, pertinence, need to pay attention to the employee's job responsibilities, service standards, the quality of work, plan development, all-round training through training and training, classification, so that all employees in their own IS09001 international quality management system of responsibility, work flow, clear quality standards, standardized operation work consciously. For small and medium-sized enterprises, from the establishment of the quality management system construction strategy, to the completion of construction process, to the enterprise through authentication, only the quality management work into the benign development of the beginning.

\section{The application of ISO9000 quality management system in enterprise management}

Total quality management emphasizes the full participation, emphasis on quality related all functions, emphasizes the enterprise resource use efficiency, quality management activities, its essence is the enterprise the documents in the form, to play a role, until the current filing the life stage, according to the enterprise personnel, organization, and resources, such as quality management means and methods to achieve the goal of enterprise quality management. Generally speaking, the planning of enterprise quality management system mainly includes target, system, system and feedback. For smes, these aspects are also covered. It is particularly important for smes to set goals and establish quality management leadership

Establish the responsibility of the quality management system, to ensure smooth implementation of the quality policy and quality objectives and achieve the quality management of the enterprise must clear quality function and each link of quality responsibility and related coordination, preventive and remedial measures, set up a group responsible for the quality of the performance evaluation methods as the main content and complete strict management system. For small and medium-sized enterprises, quality standards, functions and responsibilities, and corresponding rewards and punishment systems should also be printed in writing to employees of enterprises. Through accountability, ensure every employee, every job, every project, every product is under the cover of the quality management system.

The linear relationship between the nonlinear internal elements of each system refers to a linear quantization of the relationship between the internal elements of each system, through the simple mathematical relationship equation for a $\$ 1, \$ 2$ a equation and linear equation, and the nonlinear relationship between the quantitative relationship between the internal elements cannot say each system using a simple linear equation, but with some differential equations and mathematical equations to represent complex equations. The relationship between the elements in the system is nonlinear dissipative structure, it will produce nonlinear influence on system, will produce nonlinear correlation effect and critical effects of these two effects the basic power to promote the transformation of the direction of orderly dissipative system.

The quality management system of small and medium-sized enterprises depends on four factors, including management responsibility, resource management, product production process, measurement, analysis and improvement. The management responsibility of management responsibility is a key element in establishing the enterprise quality management system. Specific tasks for clear management responsibilities include the following items. Develop the quality policy of the enterprise. The quality policy proposed by the enterprise shall include the following contents: 
the level of enterprise products provided by the enterprise; The company's image and reputation in quality; Objectives of the quality of enterprise products; Measures taken to achieve quality objectives; The role of management personnel implementing quality policy.

Resource management resource management mainly includes three aspects. One is human resource management. In the enterprise quality management system, the human factor is the most important, the product is done under the direct operation of the employees. Human resource management should give full play to the role of human resources and arouse the enthusiasm of every enterprise employee. Among them, the training and human resources development is the most important part of the training, head of the quality management of enterprises, for example, employees of the enterprise to carry out the quality policy and quality objectives of education, training of new employees to carry out the quality consciousness. The second is information resource management.

Enterprise product realization process can be represented by the product quality ring. Enterprise product quality ring refers to the conceptual model of the interaction activities affecting product quality from the identification of consumers' needs to the assessment of whether these needs are met. This conceptual model exists in the process of enterprise management and enterprise products, including the summary process of consumer opinions, product design process and product production process. The quality of enterprise products is directly affected by these three processes. In the process of consumer opinion summary, employees should be determined by investigating the consumer to the enterprise product requirements and expectations, and confirm with corporate leadership has required to provide the required product production capacity and technical level, quality requirements and public commitment.

Measurement, analysis and improvement of the quality information is the basis of quality management, quality control and the foundation, the operation of the enterprise quality management system, need a effective mechanism of self-improvement, in order to identify the problems existing in the production process, and measures to solve them. In order to adapt to this requirement, enterprises need to do measurement, analysis and improvement work to carry out internal quality audit. At present, there are three main types of internal audit. The first is the quality management system audit, whose audit object is the function of the control process that has important influence on enterprise quality management. The second is the enterprise production process audit, generally is for one or a series of very specific link audit.

Through the implementation of the system, it is necessary for smes to change their quality consciousness and to understand the scientific nature and effectiveness of quality management standards from the depths of their consciousness. Therefore, all employees must be highly aware of quality management, establish the quality consciousness of all employees, and form a good quality management culture atmosphere. For small and medium-sized enterprise employees, also need to work through training, such as strengthen the publicity of ISO9000 standard to carry out, make the employees in daily work to the established on the basis of standard quality system consciously maintenance, truly form the quality culture atmosphere, maximize the maintenance of the established quality system.

Applying statistical analysis, strengthening process control with the thorough development of total quality management system, strengthening product production management, improving service quality is the new task facing every enterprise. Quality service and scientific management are inseparable from data analysis, index prediction and feasibility study. Therefore, the role of statistical analysis in enterprise management is getting more and more attention. Statisticians should perform daily statistical work and analyze the observation data.

To strengthen the supervision of quality management system and give full play to the role of quality management system, the realization of system documents is a relatively important stage in system operation. Generally, measures are taken from three aspects: first, the management of the organization and the internal audit organization shall supervise and guide the subordinates, find the problems to be properly solved, and timely feedback to the leaders and functions; Second, by the auditor or audit work, business inspection system to perform the backbone to inspect at all levels, 
activities in accordance with the requirements of the system files, report department found the problem, directed the rectification unit, perfect the running system.

Establishing the internal control mechanism of quality management system is an important guarantee to improve the effectiveness of sme quality management system. For small and medium-sized enterprises, one can establish a monitoring mechanism combining daily production inspection with centralized internal audit and self-improvement through internal audit. On the other hand, we can establish a management review and monitoring mechanism with daily management. In fact, for smes, the form of management review can be flexible and diverse. For example, it could be a full-time leader's review of the quality management system or a review of the quality management system at a leadership meeting. Review, for example, and the content of the evaluation results can also be a flexible decision, not necessarily covering all of the standard content, but after many review, covering the contents of the specified standards this year.

According to the test of the quality system operation, the company after approval, the company organization by the group internal auditors review the operation of the system, as the input into the management review and audit report of organization, guide the relevant units the inconsistency of rectifying system, and formulate corrective and preventive actions. Comprehensive analysis system, can be submitted to the external audit institutions audit certification, certification through the audit, the company shall accept supervision and regular audits and inspections external audit institutions, through internal and external supervision of power, can make the quality management system, establishing and perfecting constantly improved.

\section{References}

[1] Construction of the quality management system of the enterprise documents of the song li na: China paper download center [10-11-03]

[2] Construction source of li wenli's quality management system for small and medium-sized enterprises: Chinese thesis download center [10-07-31]

[3] Chixiangfang. Innovation research of enterprise quality management in Shanxi Province [J]. Scientific and technological intelligence development and economy, 2009, 19 (5)

[4] Song songlin. Comparative study on quality management of Chinese and foreign enterprises [J]. Guangxi quality supervision guide.

[5] Construction source of li wenli's quality management system for small and medium-sized enterprises: Chinese thesis download center [10-07-31]

[6] How to comprehensively implement ISOO9000 quality management system source: Chinese thesis download center [09-11-17]

[7] Liang ruihua. Discussion on quality management innovation of small and medium-sized enterprises [J]. Nandu school of learning, 2009, 29 (1).

[8] Li huibin, zhang mo. Analysis on the construction of enterprise quality management system [J]. Management and technology of small and medium-sized enterprises, 2009. 